\title{
Electromyographic and reflex study in idiopathic and symptomatic trigeminal neuralgias: latency of the jaw and blink reflexes
}

\author{
B. W. ONGERBOER DE VISSER AND C. GOOR \\ From the Department of Clinical Neurophysiology, Municipal Hospital Leyenburg, \\ The Hague, The Netherlands
}

SYNOPSIS Recorded jaw reflexes were studied in 51 normal subjects. In addition, the blink and jaw reflexes combined with masseteric electromyography were recorded in 17 unselected patients with facial pain. Six of these patients, including two without neurological anomalies, showed electrodiagnostic anomalies. The method proved valuable for differentiation between idiopathic and symptomatic trigeminal neuralgia.

Electrodiagnostic methods provide information concerning jaw and blink reflexes that cannot be obtained by direct observation. Correct interpretation of the findings in relation to the anatomical situation may help to determine and localize disorders.

The jaw reflex is monosynaptic (Corbin and Harrison, 1940; Szentágothaï, 1948; McIntyre, 1951 ; Hufschmidt and Spuler, 1962; Jerge, 1962). Both the afferent nerve fibres from spindles in the jaw-closing muscles and the efferent fibres to these muscles pass through the motor root of the trigeminal nerve in man (McIntyre and Robinson, 1959). Experiments in the cat have shown that cell bodies of these proprioceptive fibres are located in the ipsi- or contralateral mesencephalic nucleus of the trigeminal nerve. Collateral branches reach the motor nucleus of the trigeminal nerve in the pons, giving rise to uncrossed innervation (Smith et al., 1968).

The blink reflex elicited by electrical stimulation of the infra- and supraorbital nerves consists of two separate responses, an early ipsilateral and a late bilateral reflex (Kugelberg, 1952; Rushworth, 1962; Struppler and Dobbelstein, 1963; Gandiglio and Fra, 1967). The early reflex is transmitted through a simple arc, afferent fibres of which enter the pons through the sensory root of the trigeminal nerve (Tokun- aga et al., 1958; Kimura, 1973). The late reflex arc also passes through the sensory root and then runs centrally to the nucleus of the trigeminal spinal tract (Kugelberg, 1952; Kimura and Lyon, 1972). In both early and late reflexes, efferent impulses are transmitted through the facial nerve to the orbicularis oculi muscles (Kugelberg, 1952; Rushworth, 1962; Kimura et al., 1969, 1970). It is not yet certain whether the early reflex is myotatic (Kugelberg, 1952; Moldaver, 1973) or cutaneous (Shahani and Young, 1968; Shahani, 1970, 1972).

The parameters of the blink reflex have been determined by various investigators (Kugelberg, 1952; Rushworth, 1962; Kimura et al., 1963) and were confirmed by earlier findings in our laboratory. For the jaw reflex, however, little information is available (Goodwill, 1968; Kimura et al., 1970). The present study was, therefore, performed in a group of normal individuals.

The electrodiagnostic methods were evaluated in an unselected group of patients with trigeminal neuralgia as the most important symptom. For this purpose, electromyograms were made of the orbicularis oculi and masseter muscles; the jaw and blink reflexes were recorded, and when a peripheral facial nerve disorder was suspected the latency of the direct response in the orbicularis oculi muscle was also measured. 


\section{METHODS}

Seventeen unselected patients (nine women and eight men) with trigeminal neuralgia were studied. The ages ranged from $\mathbf{4 0}$ to 80 years. At the time of the electrodiagnostic investigation all of the patients were taking carbamazepine or diphenylhydantoin or a combination of these drugs. The unilateral neuralgic symptoms were in the first trigeminal division in three patients, second division in 13, and first and second divisions in one.

The control series for the jaw reflex consisted of 51 normal subjects (18 women and 33 men) ranging in age from 20 to 80 years. The subjects were divided into 10 year age groups (Table 1 ).

TABLE 1

LATENCY OF THE JAW REFLEX IN 51 NORMAL SUBJECTS

\begin{tabular}{lcccccc}
\hline $\begin{array}{c}\text { Age group } \\
\text { (yr) }\end{array}$ & $20-30$ & $31-40$ & $41-50$ & $51-60$ & $61-70$ & $71-80^{*}$ \\
$\begin{array}{c}\text { Subjects } \\
\text { (no.) }\end{array}$ & 9 & 7 & 10 & 10 & 6 & 4 \\
$\begin{array}{c}\text { Mean latency } \\
\text { (ms) }\end{array}$ & $7 \cdot 0$ & $7 \cdot 0$ & $7 \cdot 4$ & $7 \cdot 8$ & 8.4 & $7 \cdot 8$ \\
$\begin{array}{c}\text { Range } \\
\text { (ms) }\end{array}$ & $6 \cdot 4-7 \cdot 8$ & $6 \cdot 4-8.0$ & $6 \cdot 6-9 \cdot 2$ & $6 \cdot 4-9 \cdot 2$ & $8 \cdot 4-8.4$ & $7 \cdot 2-8 \cdot 6$ \\
\hline
\end{tabular}

* Bilateral negative jaw reflex in five patients.

The neurological examination was followed by analysis of the cerebrospinal fluid, electroencephalography, and radiography of the skull, basal skull, and petrosal bones.

To elicit the jaw reflex, the examiner's finger was

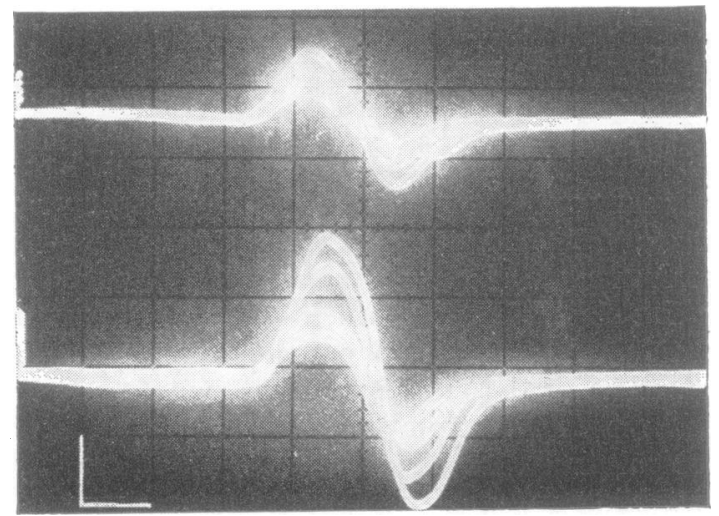

Fig. 1. Normal jaw reflex. Calibrations: $2 \mathrm{~ms}$ horizontal line) and $100 \mu \mathrm{V}$ (vertical line). placed on the patient's chin and tapped with the reflex hammer, which triggered the sweep of a dualtrace persistence oscilloscope of the electromyograph by a microswitch.

The potentials evoked in both masseter muscles were simultaneously recorded with surface electrodes (Fig. 1). The sweeps of the oscilloscope were photographed with a Polaroid camera. The latencies were measured from stimulus to initiation of the evoked potential. In addition, the amplitude and duration of the potentials from the beginning to the peak of the last major deflection were determined.

The supraorbital nerves were stimulated percutaneously by square wave electrical stimuli lasting $0 \cdot 1-0 \cdot 3 \mathrm{~ms}$. The reflexes were recorded simultaneously from the inferior half of the right and left orbicularis oculi muscles by coaxial needle electrodes. The evoked potentials were visualized in the same way as described for the jaw reflex. The latencies of the early and late reflexes were measured from stimulus to the beginning of the initial deflection of the action potential. A difference in latenco $v$ between the right and the left side exceeding $1.5 \mathrm{~ms}$ for the early reflex and $8.0 \mathrm{~ms}$ for the late reflex was considered abnormal. The absolute values of the latencies and the amplitude and duration of the responses are less useful as parameters, because of the relatively wide normal range. The direct response $\vec{Z}$ in the orbicularis oculi muscle was obtained by stimulation of the facial nerve for $0 \cdot 1-0.3 \mathrm{~ms}$ with the cathode placed just anterior to the mastoid pres cess. A response latency exceeding $5 \mathrm{~ms}$ was con sidered to be pathological.

\section{RESULTS}

NORMAL JAW REFLEX The mean latency from stimulus to initiation of the evoked potential $\frac{\triangle}{\triangle}$ was $7.6 \mathrm{~ms}$ on both sides, with a standard deviation of $1.3 \mathrm{~ms}$ and a range of $6.4-9.2 \mathrm{~ms}$ on each side. The mean latency increased from $7.0 \mathrm{~ms}$ in the 20-30 year age group to $8.4 \mathrm{~ms}$ for the $60-70$ 居 year group (Table 1). In the age group of 70-80 years the jaw reflex was absent in five out of nine subjects. In all subjects under the age of $70^{\circ}$ years the jaw reflex was present bilaterally.

There was no latency difference between the 8 right and left sides in 39 subjects. In the remaining 12 the greatest difference was $0.4 \mathrm{~ms}$. For allo age groups the mean difference between the right-sided and left-sided responses was $0.07 \mathrm{~ms}$ 을. with a standard deviation of $0.15 \mathrm{~ms}$. The dura- N tion and amplitude of the responses was quite 
variable, which is in agreement with the findings of Goodwill (1968).

FINDINGS IN THE PATIENTS (Table 2) There were no abnormal neurological or electrodiagnostic findings in 11 of the patients (group A). Four patients showed both neurological and electrodiagnostic anomalies (group C). In two patients the neurological findings were normal and the electrodiagnostic findings abnormal (group D). None of the patients had neurological anomalies with normal electrodiagnostic findings (group B).

TABLE 2

FINDINGS IN 17 PATIENTS

\begin{tabular}{cccc}
\hline Group & $\begin{array}{c}\text { Number } \\
\text { of patients }\end{array}$ & Neurological & Electrodiagnostic \\
\hline A & 11 & - & - \\
B & 0 & + & - \\
C & 4 & + & + \\
D & 2 & - & + \\
\hline
\end{tabular}

$+=$ abnormal.

$-=$ normal.

\section{CASE HISTORIES IN GROUPS C AND D (Table 3) Group C}

CASE 1 A 69 year old man had a one year history of constant first-division trigeminal neuralgia on the right, which had developed about one month after a road accident.

There was sensory loss over the distribution of the first division on the right distally from a $2 \mathrm{~cm}$ long

TABLE 3

FINDINGS IN THE SIX ANOMALOUS PATIENTS

\begin{tabular}{|c|c|c|c|c|c|c|c|}
\hline \multirow{3}{*}{$\begin{array}{c}\text { Patient } \\
\text { no. }\end{array}$} & \multirow[t]{3}{*}{ Group } & \multicolumn{2}{|c|}{ Jaw reflex } & \multicolumn{2}{|c|}{ Blink reflex } & \multirow{2}{*}{\multicolumn{2}{|c|}{$\begin{array}{l}\text { EMG of } \\
\text { masseter }\end{array}$}} \\
\hline & & \multirow[t]{2}{*}{ Right } & \multirow{2}{*}{ Left } & \multirow[t]{2}{*}{ Right } & \multirow{2}{*}{ Left } & & \\
\hline & & & & & & Right & Left \\
\hline 1 & C & + & + & - & + & + & + \\
\hline 2 & C & + & + & + & - & + & + \\
\hline 3 & C & + & + & + & - & + & - \\
\hline 4 & C & - & - & + & - & + & - \\
\hline 5 & D & - & + & + & + & - & + \\
\hline 6 & D & - & + & + & + & + & + \\
\hline
\end{tabular}

$+=$ Normal.

$-=$ Abnormal. scar over the right orbital angle. The electromyograms were normal.

The early blink reflex was absent on the right and of normal latency $(10 \mathrm{~ms})$ on the left. The bilateral late reflex to right-sided stimulation was absent, and bilaterally normal ( $32 \mathrm{~ms}$ latency) to left-sided stimulation. The jaw reflex was normal $(8.4 \mathrm{~ms}$ latency) bilaterally.

At operation, the right supraorbital nerve was found to be intersected and incorporated into the scar tissue.

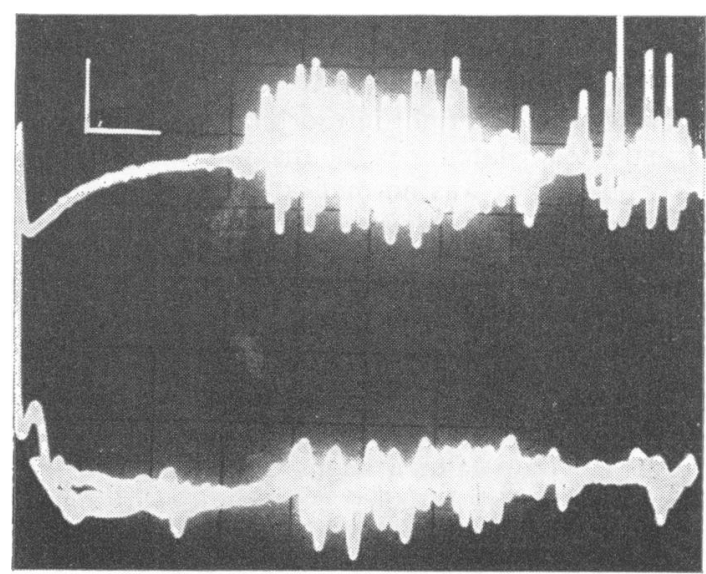

FIG. 2. Case 2. Abnormal blink reflex evoked by electrical stimulation of the left infraorbital nerve. Calibrations: $10 \mathrm{~ms}$ (horizontal line) and $500 \mu \mathrm{V}$ (vertical line).

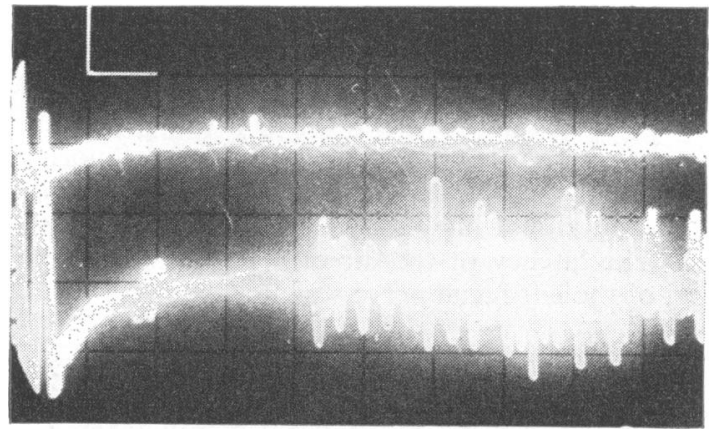

FIG. 3. Case 4. Abnormal blink reflex evoked by electrical stimulation of the left supraorbital nerve. Calibrations: $5 \mathrm{~ms}$ (horizontal line) and $500 \mu \mathrm{V}$ (vertical line). 
CASE 2 A 68 year old man gave a five year history of relapsing second division neuralgia on the left, which had developed soon after a head injury. There was a hypalgesic spot $2 \mathrm{~cm}$ in diameter, over the left cheek. Skull radiographs showed a fracture through the left infraorbital canal. The electromyograms were normal.

The latency of the early blink reflex was normal on both the right $(13 \mathrm{~ms})$ and the left $(12 \mathrm{~ms})$. The latency of the bilateral late reflex was normal after stimulation on both the right $(38 \mathrm{~ms})$ and left $(34$ ms). The early reflex after stimulation on the infraorbital nerve was significantly delayed $(20 \mathrm{~ms})$ on the left as compared with the right $(12 \mathrm{~ms})$. The late reflex after stimulation of the left infraorbital nerve showed a delayed latency ( $39 \mathrm{~ms})$ on the left as compared with the latency $(31 \mathrm{~ms})$ on the right (Fig. 2). Stimulation of the right infraorbital nerve evoked a normal latency late reflex $(36 \mathrm{~ms})$ bilaterally.

The jaw reflex was normal on both the right (8.6 ms latency) and the left ( $8.4 \mathrm{~ms}$ latency). Because conservative treatment was unsuccessful, an operation according to Dandy was performed. The surgical results were not satisfactory either.

CASE 3 A 52 year old woman initially had neuralgic pain in the distribution of the first branch on the left. Three days later a slight dysarthria and dysphagia developed. Physical examination during the next three days revealed hypalgesia over the left side of the face, nystagmus, and a left-sided peripheral facial palsy. Lumbar puncture showed 155 lymphocytes per $\mathrm{mm}^{3}$ and a normal protein level $(36 \mathrm{mg} /$ $100 \mathrm{ml}$ ). The diagnosis was polyneuropathy of the cranial nerves of unknown origin. This patient recovered spontaneously.

Eighteen days after the onset of the symptoms, electrodiagnostic investigations were performed. The electromyograms demonstrated denervation potentials in the distribution of the trigeminal, facial, and hypoglossal nerves on the left. The jaw reflex latency was normal $(6.4 \mathrm{~ms})$ bilaterally. The early blink reflex was normal (8 ms latency) on the right and absent on the left. The late reflex was of normal latency $(30 \mathrm{~ms})$ bilaterally after stimulation on the right and absent bilaterally after stimulation on the left. The latency of the direct response to stimulation of the left facial nerve was normal $(3.5 \mathrm{~ms})$.

CASE 4 A 59 year old man with a 12 year history of relapsing second division neuralgia on the left, had sustained a head injury 21 years before. After this accident, a slight left-sided pyramidal tract syndrome had persisted.

The electromyograms were normal. The latency of the early blink reflex was normal on the right $(7 \mathrm{~ms})$
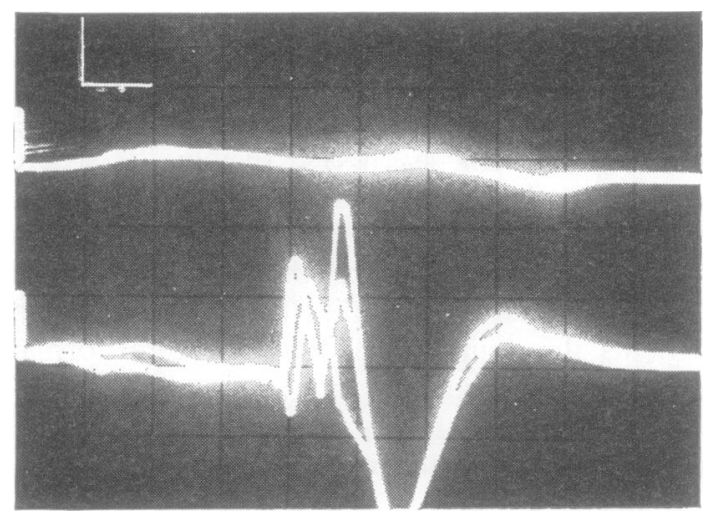

FIG. 4. Case 5. Abnormal jaw reflex. Calibrations: $2 \mathrm{~ms}$ (horizontal line) and $100 \mu \mathrm{V}$ (vertical line).

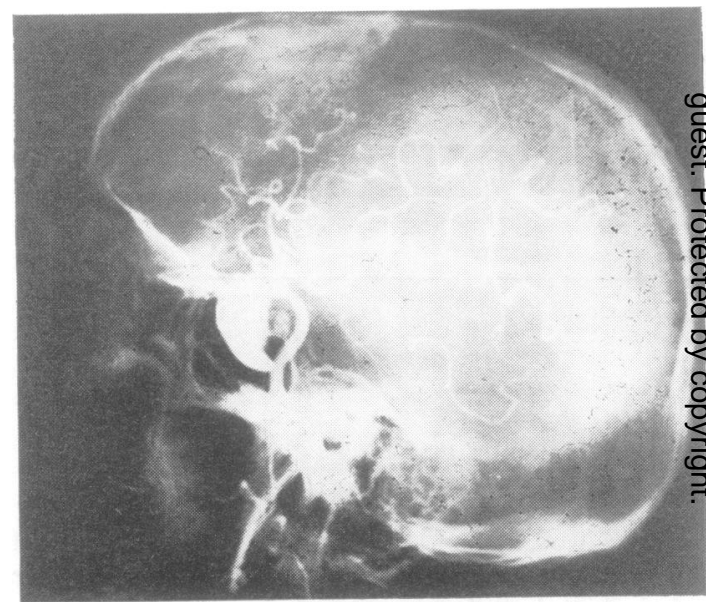

FIG. 5. Case 5. Aneurysm of the syphon of the right internal carotid artery.

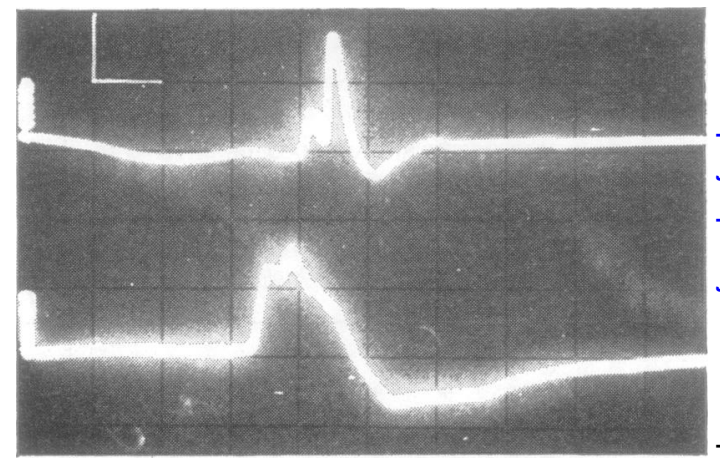

FIG. 6. Case 6. Abnormal jaw reflex. Calibrations: $\mathrm{N}$ $2 \mathrm{~ms}$ (horizontal line) and $100 \mu \mathrm{V}$ (vertical line). 
and on the left $(8 \mathrm{~ms})$. The late reflex latency was normal on the right $(26 \mathrm{~ms})$ and on the left $(24 \mathrm{~ms})$ after right sided stimulation and was absent on the right and of normal latency $(21 \mathrm{~ms})$ on the left after left sided stimulation (Fig. 3). The jaw reflex was bilaterally absent.

Conservative treatment was not successful.

\section{Group D}

CASE 5 A 54 year old woman was referred for investigation because of a 13 year history of relapsing first division trigeminal neuralgia on the right side.

The electromyograms showed denervation potentials in the right masseter muscle and were normal for the left masseter muscle.

The early blink reflex latency was normal on both the right $(13 \mathrm{~ms})$ and left $(14 \mathrm{~ms})$. The bilateral late reflex was of normal latency after stimulation on the right $(32 \mathrm{~ms})$ and on the left $(33 \mathrm{~ms})$.

The jaw reflex was absent on the right and of normal latency (7.6 ms) on the left (Fig. 4). Carotid angiography revealed a large saccular aneurysm on the syphon of the right internal carotid artery (Fig. 5).

CASE 6 A 63 year old woman was referred because of a relapsing second division neuralgia on the right lasting for two years.

The electromyograms were normal. The latency of the early blink reflex was normal on both the right $(13 \mathrm{~ms})$ and the left $(12 \mathrm{~ms})$. The bilateral late reflex had normal latency after stimulation on the right ( 32 $\mathrm{ms})$ and on the left $(28 \mathrm{~ms})$. The jaw reflex was significantly delayed $(8.0 \mathrm{~ms})$ on the right as compared with the left $(6.4 \mathrm{~ms})$ (Fig. 6).

At operation, the choroid plexus was found to bulge out of the foramen of Luschka between the complex of the glossopharyngeal, vagal, and hypoglossal nerves. The right half of the brain-stem was pushed up. The trigeminal nerve was stretched.

Two months postoperatively, the early reflex was significantly delayed $(18 \mathrm{~ms})$ on the right as compared with the left $(11 \mathrm{~ms})$. The bilateral late reflex was normal after stimulation on both the right (32 $\mathrm{ms})$ and the left $(26 \mathrm{~ms})$. The electromyograms were again normal. The jaw reflex was still considerably slower $(7.6 \mathrm{~ms})$ on the right than on the left $(6.8 \mathrm{~ms})$.

\section{DISCUSSION}

In all of the 42 normal subjects under the age of 70 years the jaw reflex was present bilaterally. Apparently this reflex is generally present, although with routine observation it often seems to be absent (De Jong, 1967; Taverner, 1968).
Only in the individuals over the age of 70 years was the jaw reflex bilaterally absent in five out of nine subjects. Consequently, the recording of a bilaterally negative jaw reflex is not a pathological finding at advanced ages.

The latency could be measured accurately. The wide range of latency $(6 \cdot 4-9 \cdot 2 \mathrm{~ms})$ means that an interindividual comparison is of no practical value. However, comparison in one subject between the latencies simultaneously recorded on the two sides appeared to be of great value. A latency difference of more than $0.5 \mathrm{~ms}$ was considered to be a pathological finding. A consistent unilateral absence of the jaw reflex was also regarded as pathological. Bilateral absence of the jaw reflex under the age of 70 years proved to be suggestive of a disorder. A wider range of latency increases the mean latency at older ages (Table 1). The mean latency of $7.6 \mathrm{~ms}$ found by us agrees reasonably well with the values reported by Kugelberg (1952) ( $7.5 \mathrm{~ms}$, but without mention of ages) and Kimura et al. (1970) (7.08 ms); Goodwill (1968) found a mean latency of $8.4 \mathrm{~ms}$. The number of subjects over the ages of 50 years examined by Kimura et al. (up to 60 years) and Goodwill (up to 56 years) is limited. In the present study the value of an electromyographically recorded jaw reflex in trigeminal neuralgia was demonstrated in case 4 (bilateral absence at the age of 59 years), case 5 (unilateral absence), and case 6 (latency difference of $1.6 \mathrm{~ms}$ ).

Disturbances of the blink reflex were present in four cases, among which the early and late reflexes were abnormal on the same side as the neuralgia in three cases and the late reflex only was abnormal in one case on the same side as the neuralgia.

The 11 patients without electrodiagnostic abnormalities also showed no neurological or other disorders during the follow-up period. The diagnosis in these cases was tentatively idiopathic trigeminal neuralgia. Conservative treatment was successful in nine patients and unsuccessful in two. In these two patients the neuralgia disappeared after a Dandy operation.

Four patients (group C, Table 2) showed both neurological and electrodiagnostic anomalies. The diagnoses were symptomatic trigeminal neuralgia due to a peripheral nerve lesion in cases 1 and 2, polyneuropathy of several cranial 
nerves in case 3 , and a brain-stem lesion in case 4. The reflex studies and the electromyograms were of great help in localizing the lesions.

Of special interest were the two cases (group D, Table 2) in which no neurological anomalies were found. The electrodiagnostic investigation made it possible to differentiate between idiopathic trigeminal neuralgia and a symptomatic neuralgia due to compression by an aneurysm in case 5 and a retro-Gasserian nerve lesion in case 6. Furthermore, a striking feature in these cases was that only the trigeminal motor root function was disturbed: in case 5 both the jaw reflex and the masseteric electromyogram and in case 6 the jaw reflex. In both patients the motor root may be responsible for the pain syndrome. This suggestion agrees with the explanation given by Saunders et al. (1971).

An impression of the function of the trigeminal motor root was obtained from the jaw reflex and the electromyograms of the masseteric muscles. The combined evaluation was useful, because one of the two was disturbed in cases 3,4 , and 6 and both were anomalous only in case 5 .

A combined analysis of the trigeminal motor root function on the basis of the jaw reflex and electromyograms and of the trigeminal sensory function on the basis of the blink reflex also seems important. Motor and sensory disorders can supplement each other, as in cases 3 and 4, or occur separately, as in cases $1,2,5$, and 6 (Table 3).

The present study confirms the value of electrodiagnostic methods in trigeminal neuralgia for the differentiation of idiopathic trigeminal neuralgia from other pain syndromes due to trigeminal nerve lesions.

We wish to thank our colleagues, particularly L. J. Endtz, O. G. Mulder (Department of Neurology), and N. Lambooy (Department of Neurosurgery), for referring their patients.

\section{REFERENCES}

Corbin, B. K., and Harrison, F. (1940). Function of mesencephalic root of fifth cranial nerve. Journal of Neurophysiology, 3, 423-435.

De Jong, R. N. (1967). The trigeminal nerve. In The Neurologic Examination, 3rd edn, pp. 224-225. Harper and Row: New York.

Gandiglio, G., and Fra, L. (1967). Further observations on facial reflexes. Journal of the Neurological Sciences, 5, 273285.
Goodwill, C. J. (1968). The normal jaw reflex: measurement of the action potential in the masseter muscles. Annals of Physical Medicine, 9, 183-188.

Hufschmidt, H.-J., and Spuler, H. (1962). Mono- and polysynaptic reflexes of the trigeminal muscles in human beings. Journal of Neurology, Neurosurgery, and Psychiatry, 25, 332-335.

Jerge, C. R. (1963). Organization and function of the trigeminal mesencephalic nucleus. Journal of Neurophysiology, 26, 379-392.

Kimura, J. (1973). The blink reflex as a test for brain-stem and higher central nervous system function. In New Developments in Electromyography and Clinical Neurophysiology, vol. 3, pp. 682-691. Edited by J. E. Desmedt. Karger: Basel.

Kimura, J., and Lyon, L. W. (1972). Orbicularis oculi reflex in the Wallenberg syndrome: alteration of the late reflex by lesions of the spinal tract and nucleus of the trigeminal nerve. Journal of Neurology, Neurosurgery, and Psychiatry, 35, 228-233.

Kimura, J., Powers, J. M., and Van Allen, M. W. (1969). Reflex response of orbicularis oculi muscle to supraorbital nerve stimulation. Archives of Neurology, 21, 193-199.

Kimura, J., Rodnitzky, R. L., and Van Allen, M. W. (1970). Electrodiagnostic study of trigeminal nerve. Neurology (Minneap.), 20, 574-583.

Kugelberg, E. (1952). Facial reflexes. Brain, 75, 385-396. McIntyre, A. K. (1951). Afferent limb of the myotatic refle arc. Nature, 168, 168-169.

McIntyre, A. K., and Robinson, R. G. (1959). Pathway fop the jaw-jerk in man. Brain, 82, 468-474.

Moldaver, J. (1973). Some comments on blink reflexes. New Developments in Electromyography and Clinical Neurophysiology, vol. 3, pp. 658-659. Edited by J. E. Desmedt. Karger: Basel.

Rushworth, G. (1962). Observations on blink reflexes. Journal of Neurology, Neurosurgery, and Psychiatry, 2 93-108.

Saunders, R. L., Krout, R., and Sachs, E., Jr (1971). Mas cator electromyography in trigeminal neuralgia. Neurology (Minneap.), 21, 1221-1225.

Shahani, B. T. (1970). The human blink reflex. Journal of $\$$ Neurology, Neurosurgery, and Psychiatry, 33, 792-800.

Shahani, B. T., and Young, R. R. (1968). A note on blink reflexes. Journal of Physiology, 198, 103-104P.

Shahani, B. T., and Young, R. R. (1972). The cutaneous nature of the first component of the monkey's blink reflex.? (Abstract.) Neurology (Minneap.), 22, 438.

Smith, R. D., Marcarian, H. Q., and Niemer, W. T. (1968). Direct projections from the masseteric nerve to the mesen-O음 cephalic nucleus. Journal of Comparative Neurology, 133, 495-502.

Struppler, A., and Dobbelstein, H. (1963). Elektromyo-O graphische Untersuchung des Glabellareflexes bei ver-schiedenen neurologischen Störungen. Nervenarzt, 34, 347352.

Szentágothaĩ, J. (1948). Anatomical considerations of mono-음 synaptic reflex arcs. Journal of Neurophysiology, 11, 445-3. 454.

Taverner, D. (1968). The localisation of isolated cranial nerve lesions. In Handbook of Clinical Neurology, vol. 2, p.? 57. Edited by P. J. Vinken and G. W. Bruyn. North-Hol-O land: Amsterdam.

Tokunaga, A., Oka, M., Murao, T., Yokoi, H., Okumura, T. Hirata, T., Miyashita, Y., and Yoshitatsu, S. (1958). An已. experimental study on facial reflex by evoked electromyof graphy. Medical Journal of Osaka University, 9, 397-411. 